\title{
Arbor
}

\section{La multinacionalidad en el campo de la defensa}

\author{
José Manuel García Sieiro
}

Arbor CLXV, 651 (Marzo 2000), 371-396 pp.

\section{Ante el nuevo orden mundial}

El concepto de Nuevo Orden Mundial marca más la obsolescencia del orden bipolar para articular las relaciones internacionales de posguerra fría que la existencia de un nuevo orden alternativo. En estas condiciones de incertidumbre sobre el contexto externo de seguridad, se necesita un liderazgo que señale nuevos objetivos, decida las políticas y estrategias necesarias para llevarlos a cabo y que, al hacerlo, gestione la transición hacia el nuevo orden. Hasta ahora, el actor esencial de la seguridad, la economía y las relaciones internacionales ha sido el estado-nación y en este marco estatal se ha basado la formación y experiencia de las personas que ejercen algún tipo de liderazgo o dirección. Ahora bien, si tenemos en cuenta que el estado-nación ha entrado en una situación de crisis que afecta a su identidad - aunque no a su supervivencia-, deberíamos analizar las tensiones centrífugas y centrípetas que se detectan, sobre todo en lo referente a las uniones supranacionales y comprobar o corregir las posibles actitudes de liderazgo para adecuarlas a los nuevos tiempos, sin olvidar que en el futuro convivirán actores transnacionales, intergubernamentales, supranacionales, supraestatales y subestatales que interactuarán entre sí y con el estado-nación.

Entendemos por actores transnacionales los que actúan por encima del control del estado, como empresas multinacionales, asociaciones internacionales públicas o privadas, ONG,s., Medios de Comunicación Social (MCS.), ... Por intergubernamentales entendemos aquellos actores en los que el papel del estado es relevante, como las Organizaciones Intergubernamentales (OIG.) de NN.UU., OSCE., OTAN, UEO... Su- 
pranacionales son aquellas OIG que han recibido desde los estados la transferencia del ejercicio - que no la titularidad- de una competencia propia de la soberanía estatal, caso de la Comunidad Europea, de las Relaciones Exteriores de la Unión, o de la Política de Defensa Común de la misma. Finalmente, actores supraestatales son aquellos actores que pueden surgir cuando los estados les transfieran su titularidad, caso de la hipotética Defensa Común de la Unión y de la propia Unión Europea, si culmina con éxito su proceso de integración. Los subestatales, como regiones y comunidades locales no parecen llamados a asumir competencias de seguridad y defensa, pero, sin duda tienen su efecto en estos campos aunque en este momento no es fácil predecir cuál será.

Es necesario pues, no olvidar que hay otras muchas formas de entender la política, la diplomacia, la seguridad... en un posible nuevo orden, donde la existencia de varios centros de poder por todo el globo y las comunicaciones modernas, exigen nuevas formas de afrontar los problemas de todo tipo y sobre todo los de seguridad. Por otro lado, las percepciones del peligro son muy diferentes, por lo que la habilidad de captar situaciones y sensibilidades diferentes se hace casi imprescindible para los dirigentes.

Pero sigamos analizando las circunstancias de este nuevo mundo al que nos dirigimos. En él se darán curiosas contradicciones como pérdidas o cesiones de soberanía de los estados-nación en favor de los emergentes entes supranacionales y, simultáneamente, un mayor peso de los gobiernos regionales o municipales (globalidad versus regionalismo). Asimismo, se tomarán decisiones importantes por empresas transnacionales, y el peso de organizaciones no gubernamentales (ONG) alcanzarán cotas de influencia cada vez mayores, todo ello en un mundo donde las grandes redes de comunicación, con su gran poder, difuminan las fronteras, hasta ahora netamente definidas, y acercan a las personas las noticias, aunque, eso sí, con diferente intensidad según el nivel de desarrollo de cada país, y esto es algo que no se debe olvidar, sobre todo en el campo que estamos analizando, en el ámbito de la SEGURIDAD y DEFENSA.

Lo anterior es clave, pues la percepción de los conflictos, de las amenazas y riesgos $\mathrm{y}$, por consiguiente, de los sentimientos de miedo y odio, es muy diferente según el desarrollo cultural, económico y científico de los pueblos y, por ello, va a ser determinante en las relaciones entre ellos. En este punto sería necesario recordar las reflexiones de SAMUEL P. HUNTINGTON cuando analiza el «choque de civilizaciones» que podríamos resumir en que los contactos de todo tipo, entre las 
diferentes civilizaciones, son cada vez más frecuentes y, por ello, los riesgos de posibles conflictos aumentan por razones obvias y obliga a los líderes de todas las partes a hacer enormes esfuerzos de imaginación $\mathrm{y}$, muchas veces, generosidad para evitar confrontaciones.

En el campo de seguridad y defensa, y tomando el caso de Europa, observamos que, en los actores que afrontan la integración, se encuentran todos los obstáculos que señalaba TONNIES para pasar de una Sociedad europea fragmentada a una Comunidad europea con un alto grado de cohesión interna y con lazos de agregación entre sus miembros. Por eso, el liderazgo de la integración precisa establecer, mediante la comunicación, las condiciones estructurales necesarias para que la integración pueda desarrollarse sin la animadversión de las élites contrarias o el distanciamiento de las sociedades civiles.

No debemos olvidar que en el fondo de todo el proceso de integración se encuentra el debilitamiento del estado-nación, y es por ello, que la trasferencia de competencias, como medio de materializar esa integración, se encuentre en momentos de avances, retrocesos y titubeos. Quizás la explicación sería que los estados-nación se resisten a ceder soberanía por miedo a la incertidumbre o ¿porqué no? por vislumbrar que la integración regional será sólo un paso para una integración aun de más alcance de tipo global, y esto se ve quizás más claro en el campo de la seguridad, donde el concepto de globalidad se abre paso cada vez con más fuerza. Ahora bien, estas diferencias de ritmo crean tensiones por la diferente visión de los grandes temas, y por ello se producen situaciones difícilmente explicables si no se contempla la situación de forma sistémica.

Ahora bien, las iniciativas para dotarse de un mecanismo común de seguridad, como el de Política Exterior y Seguridad Común (PESC.) está muy ligada a la evolución del estado nación pues la cesión de soberanía es prácticamente el último paso a su desaparición. Sin embargo, la necesidad de avanzar hacia un mecanismo de defensa común de seguridad colectiva ha suscitado el inicio de una cooperación intensa en este campo que ha cristalizado con la creación de unidades multinacionales europeas (EUROCUERPO, EUROFOR, EUROMARFOR) de indudable importancia y que trataremos más adelante en profundidad.

Por lo anterior, podemos resumir que en el campo de la Iniciativa Europea de Seguridad y Defensa (IESD.), los papeles están repartidos entre la Seguridad para la UE y la Defensa para la UEO. Sin embargo, el tema clave está en la toma de decisiones, donde el factor tiempo será crucial y en la que influirá claramente el o los órganos ejecutivos que se arbitren y el procedimiento, consenso o mayoría, que se articule. 
Si continuamos en el plano operativo, hay instrumentos multinacionales militares preparados, conceptos de apoyo como el Combined Joint Task Force (CJTF.) y unos sistemas operativos que avanzan razonablemente bien. En fin, en la IESD. existe una arquitectura casi dispuesta para hacer realidad una futura integración dentro de la UE. del pilar europeo de Seguridad y Defensa y sólo falta una clara intención política que vertebre todo el sistema.

\section{Epoca de cambio}

Vemos, por un lado, que estamos ante situaciones nuevas que exigen nuevas necesidades, de las que se derivan nuevas misiones y que requieren instrumentos y técnicas diferentes. Por otro, hay que considerar la formación, la mentalidad y la propia personalidad de los Ejércitos como organizaciones e instituciones que evoluciona a buen ritmo, pero nunca tan rápido como los acontecimientos.

Para entender estas nuevas situaciones y sus implicaciones en los Ejércitos y las personas que los forman es imprescindible analizar el concepto de «cambio» en toda su dimensión. «El cambio es lo único que permanece» (Heráclito). Es posible y necesario. Es global y afecta no sólo a las naciones, sino a la sociedad mundial. Es neutro, es decir, ni positivo ni negativo, simplemente existe.

El cambio o crisis, como también puede denominarse siempre que no caigamos en la costumbre, extendida hoy día, de aplicar el concepto de crisis a cualquier situación y normalmente en sentido negativo, se está operando en múltiples sectores de la vida mundial. Pero, quizá, uno de las más importantes o, más bien, el origen de todos, es el paso de individuo a persona. En la conjunción de estos dos conceptos y en el dualismo que produce está gran parte del drama de la cultura occidental. La persona, como ser humano, percibe más claramente que nunca que ha dejado de ser una «pieza del engranaje» y que las circunstancias no tienen por qué conformar su destino, sino más bien sus propias decisiones.

Por tanto, podemos considerar que el cambio se genera en la persona, se proyecta hacia la sociedad mundial y se basa fundamentalmente en la comunicación. Conceptos como «Tercera Ola», "Aldea Global», «Revolución no Neolítica» ilustran, un poco, cómo los modernos autores perciben el cambio en los albores del siglo XXI. 


\section{La multinacionalidad en el campo de la defensa}

El cambio o crisis tiene dos componentes: riesgo y oportunidad. El conjugar las acciones que contemplan ambos parámetros es la clave para el «manejo del cambio».

Hay, por último, otro concepto interesante y es la relación entre cambio y tensión. Todo cambio produce tensión pero, también la tensión es la que favorece el cambio y ejemplos en la historia mundial nos lo demuestran. Así, la tensión creada entre las diferentes clases sociales durante la Revolución Industrial fue, sin duda, motivo de no pocos problemas pero, al mismo tiempo, fue imprescindible para dinamizar el mundo cuyo avance alcanzó perfiles de progresión geométrica en todos los campos de la vida. Todo lo expresado, en general, tiene su reflejo, como es lógico, en los Ejércitos.

Asimismo, debemos considerar, dentro del cambio, la trascendencia del concepto de Patria. Nadie puede olvidar su significado en este momento histórico, pero la espiral evolutiva va abriendo, cada vez un poco más, su radio y el concepto de multinacionalidad en la organización de los Ejércitos modernos, nos sugiere que el servicio que debemos prestar, y por el que morir si fuera necesario, ya no es sólo por la nación propia, sino por la sociedad, entendida en su más amplio significado.

Por último, es en esta última década cuando los Ejércitos tienen que enfrentarse a cambios radicales en el entorno, de todo signo y naturaleza: nuevas misiones, nuevos riesgos producidos por situaciones geoestratégicas cambiantes, menos recursos, etc. ... que obligan a responder, buscando soluciones. En cualquier caso, la evolución continuará, pues las sociedades y sus Ejércitos lo hacen con, o a pesar de las personas. El problema se reduce a manejar el cambio o a ser arrastrados por él.

De nuestra capacidad para controlar y manejar este cambio se derivarán nuestras capacidades para conseguir un instrumento eficaz, unos Ejércitos adecuados y potentes.

El cambio no tiene por qué ser disgregador sino integrador y, precisamente, en la integración de los conceptos tradición y modernidad y en su inteligente conjugación, está una de las claves del éxito para el futuro de los Ejércitos. Éstos no son la únića institución que posee valores, pero sí es cierto que por su organización, principios, misión y estilo de vida están en las mejores condiciones de aportar personas que sean realmente útiles a la sociedad y ser, con su ejemplo constante de servicio, un catalizador de la misma.

Estos valores están en la mente de todos y no se trata de hacer una relación detallada con sus correspondientes definiciones pero, en 
su conjunto, resumen esa forma especial de entender la vida como un servicio, y con la suprema finalidad de conseguir la paz. Con el riesgo que se corre al simplificar, diríamos que sería «el espíritu de caballero» tan tratado desde el punto de vista literario, el que mejor resume los valores tradicionales que conforman la moral militar y que, lejos de parecer arcaicos, están más al día que nunca y si no, véanse las misiones nuevas que están llevando a cabo los Ejércitos. En esta línea, el papel de los Ejércitos ya no es tanto el «sostén del poderoso» sino, más bien, el «protector del débil».

Todo lo que podríamos seguir analizando nos lleva siempre a las personas, que son el capital más importante de los Ejércitos y su mayor aportación y la pieza clave en el proceso de cambio.

Si el militar de carrera no percibe su profesión como una vocación, sino más bien como una ocupación remunerada, se habrá perdido una ocasión única para manejar el cambio y alcanzar un gran prestigio para la institución militar en estos momentos.

Como ya se ha dicho, todo cambio genera una tensión lógica entre la organización y sus propios componentes. Conceptos como lo que debe ser, lo que puede ser, lo que es y lo que podría ser, bullen en todas las cabezas de los responsables de tener organizado, equipado y preparado un instrumento militar necesario y suficiente en cada nación, considerando siempre que lo fundamental no es evitar las tensiones, sino más bien ser capaces de aprovechar el potencial activo de las mismas para seguir avanzando en la dirección más adecuada y coherente con el momento histórico que se vive.

La situación no es nueva y, en otros muchos momentos, los Ejércitos se han tenido que ir adaptando y adoptando diferentes estructuras, medios y procedimientos, doctrinas y reglamentos que han configurado una lógica evolución hasta los Ejércitos actuales. Pero sí hay un matiz diferencial en la situación actual, y es la rapidez del cambio, por ello, todas las circunstancias que lo rodean se agrandan y generan una mayor tensión que puede hacerse difícil de superar, si no se está dispuesto y preparado para manejar y controlar ese cambio.

En este punto, sería necesario considerar que tratar de ralentizar el ritmo y disminuir la tensión puede ser un logro positivo a corto plazo, pero puede ser peligroso a medio y largo plazo. Las circunstancias del cambio están, a menudo, fuera del control de las organizaciones militares $\mathrm{y}$, por tanto, siguen su propio ritmo, que hará que éstas se alejen cada vez más de la posibilidad de ofrecer un instrumento eficaz para afrontar las nuevas situaciones y, por tanto, quedarán obsoletas. 


\section{La multinacionalidad en el campo de la defensa}

Los responsables de los Ejércitos hace años que han visto claro lo anterior, y se ha trabajado con mayor o menor fortuna, hasta definir unas organizaciones que puedan responder a las necesidades de Defensa en los albores del siglo XXI.

Ahora bien, es en la motivación donde es necesario incidir con más fuerza, cuanto más importante sea el cambio. De nada vale unas organizaciones militares impecables, con unas estructuras adecuadas y con los medios precisos si las personas que conforman y dinamizan estas estructuras no están motivadas o, lo que es lo mismo, preparadas, concienciadas y convencidas de la necesidad de evolución en esa nueva situación.

La auténtica motivación es el trabajo en sí mismo, la identificación de las personas con su labor, el sentirse satisfecho con ella y, en definitiva, cuando los fines individuales coinciden con los fines de la organización.

Por otro lado, en la motivación es fundamental la formación y la comunicación y, en ambos campos, es necesario intensificar los esfuerzos, tanto en la organización como individualmente.

Por lo anterior, la formación adquiere una importancia significativa, pues nadie se identifica con lo que no conoce en profundidad y para conocer y comprender, es necesario estar formado en el mayor grado posible. También es fundamental la comunicación, entendida en todas las direcciones: interna, para que el militar conozca en todo momento las finalidades y objetivos que debe conseguir su Ejército; externa y biunívoca, para proyectar hacia la sociedad su imagen, buscando la manera adecuada de presentarla.

$\mathrm{Y}$ es así como introducimos el concepto de liderazgo, que sería necesario analizar en profundidad. No se trata, ahora, de hacer este análisis, aunque sí de entresacar alguna idea. Por ejemplo, el liderazgo no es un concepto únicamente militar, pero es en el Ejército donde alcanza un significado especial. El liderazgo tiene más que ver con la persona que con el individuo, al ser el primero un concepto trascendente y global, acorde con los tiempos actuales.

Los líderes no deben ser, al menos a priori, unos seres especiales. Todos tenemos la obligación de procurar formarnos en esa idea, huyendo de cualquier criterio elitista. Nadie puede ser líder de nada si previamente no es capaz de ser, en sí mismo, su propio líder controlando y formando su carácter, forjado en una búsqueda constante de identidad en principios libremente aceptados.

En otro orden de ideas, hay que conseguir que los componentes de los Ejércitos presten toda su colaboración y esfuerzo, y para ello 
es muy conveniente que la sociedad sienta esa necesidad de seguridad global por la elemental razón de que el militar es un miembro de ella y, por tanto, sujeto a sus mismas influencias.

De esa forma el militar, al sentirse útil, al considerar que gracias a sus conocimientos y entrega, puede en algún momento defender a esa sociedad a la que pertenece, encuentra su más íntima motivación. De esta formà lograría alcanzar un peldaño más en la escala de necesidades que expresó MASLOW: las de estima, prestigio y respeto.

Realmente, no se discute, salvo excepciones, la necesidad de la Seguridad y Defensa, pero se juega con elementos fundamentales de ellas, con tal tranquilidad e imprudencia, que la propia idea base queda dañada seriamente. $Y$, en el medio de esta indefinición, calculada pero muy peligrosa, se encuentra el profesional de la Seguridad - el militarque tiene que trabajar en algo que se cuestiona continuamente.

Sin embargo, a pesar de todo lo dicho, debemos partir de la base de que la sociedad actual es así, ni mejor ni peor, sino que está inmersa en un proceso dinámico evolutivo en el cual todos los conceptos sufren modificaciones y sería ilusorio pensar en situaciones inamovibles o axiomáticas.

Por tanto, el concepto de Seguridad y Defensa sufre y sufrirá variaciones y vaivenes en función de multitud de factores, que impedirán una definición duradera de principios y criterios, siendo necesaria una mentalidad abierta y consciente de la evolución de las sociedades en la Historia.

En este contexto, el militar debe tener la flexibilidad como máxima y trabajar para adaptar las organizaciones de Defensa y Seguridad a lo que demanda la sociedad en cada momento, con las directrices políticas oportunas.

La habilidad del militar ha de consistir en irse adaptando, sin olvidar el fin último de seguridad de la sociedad, manteniendo su propia personalidad y tratando de ser lo más eficaz posible en una labor difícil y en ocasiones poco agradecida, por lo ya dicho.

Sin embargo, para que ese militar actúe así, es necesario que su motivación sea muy fuerte, que vea la importancia de su labor, que sea capaz de adaptarse a su entorno - vivir su tiempo - y al mismo tiempo cultivar una personalidad, si no diferente, sí diferenciada. Respecto a este último punto no olvidemos que, si el militar tuviera que ejercer su profesión en situaciones de guerra, tendría que actuar en unas condiciones especiales y ser capaz de manejarlas y cumplir su misión, procurando «humanizar» el enfrentamiento, lo cual no es fácil, 


\section{La multinacionalidad en el campo de la defensa}

y los ejemplos históricos son elocuentes. Para ello se necesita cultivar unas cualidades, algo «trasnochadas» en nuestra realidad actual, pero imprescindibles como: el espíritu caballeresco, el honor, el respeto por el enemigo, etc.

\section{Multinacionalidad}

Al hablar del concepto de multinacionalidad, no debemos referirnos a una región concreta del planeta, sino al ámbito general y en este sentido han de plantearse los conceptos y soluciones a este tema. Ahora bien, también hay que tener en cuenta que para que se produzca el fenómeno de la multinacionalidad debe darse como condición previa una cooperación política entre naciones para conseguir el acuerdo de preservar conjuntamente unos determinados intereses y eso sólo pasa cuando se conformen unas organizaciones regionales a tal fin.

Por ello, el fenómeno de la multinacionalidad se está dando con intensidad en la esfera del mundo occidental pero no se puede descartar que se vaya extendiendo a otras zonas en el futuro más como factor de estabilidad que de lo contrario y puede incluso que las experiencias obtenidas sean útiles en otras zonas como Iberoamérica y África. Además, en el ámbito mundial, bajo los auspicios de la ONU. ya se están dando algunas experiencias multinacionales que podemos llamar de «amplio espectro» aunque las misiones de ayuda humanitaria no reflejan los conceptos que aquí se exponen de multinacionalidad con características operativas que exigen una mayor integración y eficacia, lo cual de momento sólo se da en las organizaciones regionales de defensa tipo OTAN. o UEO.

Lo que tratamos a continuación se refiere a una parte del mundo en el que el desarrollo económico, cultural y político permite establecer avances en la multinacionalidad por lo expresado anteriormente. En otras zonas del mundo el desarrollo es menor y estos conceptos son de difícil aplicación, por el momento.

Si analizamos las tendencias históricas de los Ejércitos, feudal y nacional ahora ¿hacia dónde vamos? En principio y en congruencia con las tendencias políticas iríamos a una integración de tipo regional también, lo que supondría un Ejército Supranacional único para diferentes regiones que podemos considerar, si lo anterior se cumple.

En el proceso se ve claro que el Ejército o Ejércitos han de seguir las fases de la evolución política, o aún mejor de las Sociedades que son a las que sirven y ante las que tienen la responsabilidad de su 
defensa, igual que los políticos tienen la responsabilidad de dirigir a esas sociedades a mejores cotas de progreso y bienestar dentro de la inexorable evolución de la historia. Sin embargo, en lo que respecta a la Defensa hay un dato que es necesario tener en consideración; la irreversibilidad o costosa vuelta atrás de las decisiones; cosa que en los aspectos económicos, jurídicos y políticos en general no son tan delicadas.

Me explicaré; cuando un esquema defensivo se cambia, se producen ciertas vulnerabilidades, unas reales otras no tanto pero que se perciben como tales y eso provoca, o puede hacerlo, inseguridad, si no se analiza adecuadamente el entorno. Por ello, si tomamos Europa como ejemplo, dentro de la Unión, el pilar económico puede avanzar muy rápidamente, e incluso aunque con más dificultad el pilar jurídico y normativo, pero el de seguridad para que avance han de solucionarse infinidad de contradicciones y sentimientos muy arraigados.

Por tanto, procede analizar el concepto de multinacionalidad aplicado a la Defensa, para encontrar soluciones.

El esquema de la multinacionalidad, o lo que también podríamos llamar procedimiento de multinacionalidad aplicado a los mecanismos militares, no es una solución nueva en la historia en la que la dinámica de las alianzas obligó a tener que operar juntas a unidades militares de diferentes países en una determinada contienda. Ejemplos de lo anterior lo tenemos en las Cruzadas (1095-1230), la Guerra de los Treinta Años (1618-1648), la Guerra de Crimea (1853-1856), la I Guerra Mundial (1914-1918) y la II Guerra Mundial (1939-1945), entre otras.

Por tanto, no se puede decir que estemos ante un fenómeno nuevo pero sí hay un matiz claramente diferenciador. En el enfoque clásico, la multinacionalidad se producía una vez iniciado el conflicto por agregación de fuerzas nacionales o bien de órganos de mando y se buscaba el sumatorio de fuerzas para lograr cantidad y respaldo de más naciones lo que proporcionaba un valor añadido y fuerza no solamente militar.

En el nuevo enfoque se trata de institucionalizar el concepto desde tiempos de normalidad de forma que las ventajas y valores añadidos de cohesión y calidad se obtengan antes del conflicto y actúen así como un factor mas de disuasión.

Se antepone este primer activo, la disuasión, de la multinacionalidad porque es muy importante y misión primera de cualquier fuerza el disuadir al enemigo de una intervención con lo que estaríamos alcanzando los objetivos de seguridad con el coste mínimo en lo más importante, que son las vidas humanas. 


\section{La multinacionalidad en el campo de la defensa}

La experiencia, hasta ahora, como ya se ha dicho es la agregación de naciones una vez iniciado el conflicto, y si convenimos que siempre ha sido positivo para las alianzas formadas, se pretende adelantar el éxito a una fase anterior al conflicto, ejerciendo una acción importante en el escenario a considerar.

Hay otras razones que favorecen la multinacionalidad que están en el ámbito de la organización interna de cada nación en lo relativo a las Fuerzas Armadas y en sus Políticas de Defensa.

- En la organización de las Fuerzas Armadas:

La tendencia a la baja aunque, últimamente ralentizada, de los presupuestos de defensa de los países de Europa Occidental obliga a contar con aliados para cualquier intervención. Al mantener unas Fuerzas Armadas de mínimos para las necesidades nacionales se ve claro que es muy difícil realizar acciones unilaterales y de forma aislada por falta de medios. Esta tendencia no es la misma en otras regiones mundiales y por ello la predisposición a la multinacionalidad es menor.

- En las políticas de defensa:

Teniendo en cuenta los ámbitos de actuación y la menor probabilidad de actuación en el más cercano de la soberanía de cada Nación, las intervenciones más corrientes lo serán en el ámbito regional o en el mundial que siempre han de estar auspiciados por organizaciones regionales de defensa y seguridad, y por ello al depender ya de unas decisiones políticas de ámbito internacional parece más lógico plasmarlas en el campo operativo con unidades multinacionales, tanto por razones de coherencia como de respaldo político.

\section{Concepto de unidades multinacionales}

Ahora bien, para conseguir este respaldo político, los países que han de tomar la decisión de involucrar a sus fuerzas en una empresa multinacional, constituyendo Unidades multinacionales, deben sopesar cuidadosamente sus propios intereses, sus objetivos de política exterior, sus compromisos bilaterales y todo ello dentro de su entorno geoestratégico.

Como se ve, el contexto y ámbito de decisión resulta enormemente complejo, ya que supone asumir compromisos que pueden alargarse en el tiempo y comprometer a los países integrantes en una dinámica que puede variar según el transcurso de los acontecimientos.

Por todo ello, la prudencia en la toma de decisiones y el compromiso a objetivos claros de política exterior, junto al papel que cada país 
desee jugar en el campo internacional, será básico para tomar decisiones en este campo.

$\mathrm{Si}$ a la decisión política unimos la dificultad que supone el disponer de los requerimientos militares que exige la formación de unidades multinacionales, no se debe ser sólo prudente, sino también coherente $\mathrm{y}$ disponer de unas fuerzas que sean interoperables y suficientemente dotadas en medios, pues sin duda serán un exponente del prestigio de esa nación y sus funciones de mayor o menor liderazgo dentro de la Unidad multinacional favorecerá más o menos la libertad de acción de la política exterior de ese país.

Como se ve, la constitución de Unidades multinacionales, bien en permanencia o para una determinada misión, implica una importante carga política por la identificación de fines, solidaridad y decisión compartida pero además es una búsqueda de soluciones a unos cambios de estructuras defensivas que se vislumbran en un ambiente de seguridad colectiva para atender a riesgos poco definidos y a la economía de medios en el campo de la defensa.

Una vez tomada la decisión política hay también que resolver problemas técnicos de integración como es decidir cuál será el nivel de ésta, más o menos elevado, y si se hará sólo en los Cuarteles Generales o en las Unidades inferiores, pero eso se comentará más adelante.

Como vemos, al ser la decisión política y los problemas técnicos de gran dificultad, es necesario sopesar claramente las ventajas e inconvenientes que la multinacionalidad aporta a los esquemas defensivos de las Naciones que están involucradas en el proceso.

Sin duda, como ya se comentó, la principal ventaja es el efecto de disuasión que supone el que varias naciones decidan colaborar en un esfuerzo común para afrontar sus problemas de seguridad. El compromiso de actuar juntos es un valor añadido a sus respectivas potencialidades, demográficas, industriales y tecnológicas. Otra gran ventaja, comentada antes de forma somera, es la economía de medios que resulta de un reparto de costos y sacrificios en un mundo como el actual y en sociedades económicamente avanzadas donde la relación coste/eficacia es difícil de traducir al campo de la defensa, ya que el coste de la seguridad no se percibe claramente por las opiniones públicas. Los ostes de preparación de las fuerzas y su sostenimiento serían mi gravosos si se buscara la autarquía, pero si se buscan caminos de complementariedad y especialización en diversas áreas con soluciones imaginativas, el constituir fuerzas multinacionales de volumen suficiente puede resultar menos gravoso para las Naciones participantes que intentar resolver aisladamente los problemas de seguridad y de- 


\section{La multinacionalidad en el campo de la defensa}

fensa. Respecto a los sacrificios, siempre hay que tener en cuenta las posibles bajas y la opinión pública aceptaría difícilmente esta posibilidad salvo en el caso que la empresa sea lo suficientemente importante y que no estemos solos en ella.

Ahora bien, hay también inconvenientes y el más importantè es verse inmersos en algún conflicto en el que no se vea claro la defensa de los intereses particulares de una nación. El equilibrio entre la solidaridad con los otros países y el sacrificio propio debe ser el elemento clave para la decisión.

Sin embargo, los mayores problemas se dan en el campo técnico y se refieren al nivel de integración y a la cohesión de las fuerzas. Veamos algunos de ellos:

- Mando y Control: El establecimiento de la adecuada estructura de mando multinacional está aún por definir. Se ven como dos posibles. De un lado, el Cuartel General de una Fuerza Multinacional puede pertenecer a la nación que más fuerzas aporte, asignando a tal organización Oficiales de las otras Naciones para desempeñar cometidos específicos (Modelo «framework»o «leading nation»). De otra parte, puede también establecerse un Cuartel General Multinacional integrado, sin preponderancia entre Naciones y con un Mando establecido por rotación (Modelo «integrated»).

- Logística: La multinacionalidad dificulta el apoyo logístico. Parece lógico que el apoyo a las fuerzas que se aporten quede bajo la exclusiva responsabilidad de las naciones que las aportan, con independencia de su entidad. Lo anterior se matiza en el sentido de que es posible, mediante acuerdos bilaterales, obtener apoyos en elementos comunes, como por ejemplo carburantes, de otra Unidad que forma parte de la misma Fuerza Multinacional. La misma regla se aplica a la función Transporte aunque, dada la enorme necesidad que de tal función se precisa, cada Nación no debe esperar apoyos importantes, por lo que su aportación ha de medirse con cautela. Los problemas logísticos podrían reducirse en el futuro, si, como parece previsible, al nivel europeo, los Ejércitos dispusieran de un material homogéneo y muy similar.

- Interoperabilidad: Se reconocen las dificultades que pueden presentarse para constituir Grandes Unidades en las que el concepto interoperabilidad esté suficientemente desarrollado, aunque sin tal capacidad el concepto de Fuerza Multinacional no tiene aplicación práctica. Son especialmente importantes los sistemas C3I 
así como el idioma (del país «leader» o inglés) que puede limitar, en cierto modo, el adherirse a una determinada Fuerza Multinacional.

- Instrucción y Adiestramiento: Aunque la instrucción y adiestramiento en común de una Fuerza Multinacional presentan dificultades, se pretende paliarlas mediante un programa amplio de ejercicios asistidos por computadora (CAX.), de Puestos de Mando (CPX.) y con tropa reducida (CFX.). A tales ejercicios se añadirán las maniobras normales con el completo de los efectivos.

\section{EUROPA Y LA MULTINACIONALIDAD}

Para analizar la multinacionalidad, Europa es prácticamente el único ejemplo y se observan algunos elementos importantes:

- La lengua: En el mundo de la información, y con los avances técnicos cada vez más, las lenguas dejarán de ser una barrera infranqueable, al menos en las élites minoritarias que siguen y marcan los destinos de los pueblos. En el futuro el multilingüismo será un fenómeno bastante natural y fácilmente asumible.

- La cultura: De igual modo no ha de ser un elemento de separación entre los pueblos, y puede muy bien ser lo contrario, si no se hace de la misma una fortaleza de intransigencia y se produce la necesaria interrelación que sin duda enriquecerá a todos. Ahora bien, aquí pueden englobarse otros muchos conceptos producidos por la educación, la historia, las tradiciones, el ser diferenciador y es aquí donde puede encontrarse alguno de los puntos difíciles del problema.

- Los valores: En este tema se pueden analizar indicadores y hay estudios al respecto que comparan y correlacionan actitudes personales y colectivas más frecuentes en diferentes países que proporcionan unos datos que, llevados a ejes cartesianos, se observa que se producen unas agrupaciones de naciones en las cuales podemos comprobar las similitudes o afinidades que facilitarán las relaciones y el trabajo conjunto, no sólo a nivel de liderazgo, sino a nivel de ejecución, lo que en definitiva facilitará la comunicación y por tanto el trabajo conjunto-combinado de las unidades y los órganos de planeamiento y dirección. 
La multinacionalidad en el campo de la defensa

Como resumen del análisis podemos establecer que hay países con más afinidades y podríamos separar algunos grupos claros:

Grupo A: España, Francia, Italia.

Grupo B: USA., Gran Bretaña, Canadá, Países Bajos.

y quedan en una posición intermedia, acercándose a uno u otro grupo, . según los factores analizados, países como Alemania, Noruega, ...

En el ámbito de OTAN., y teniendo en cuenta la integración de nuevos países del Este europeo, se producirá la aparición de algún grupo más que será necesario analizar en el futuro.

Repasemos pues la cohesión que se desprende del anterior análisis en algunas de las fuerzas multinacionales actualmente organizadas:

EUROFOR: España, Francia, Italia y Portugal. Puede ser una Unidad muy cohesionada con un liderazgo claro de Francia.

EUROMARFOR: Mismos países. Mismo análisis.

EUROCUERPO: Alemania, Bélgica, España, Francia. También bastante cohesionada con un liderazgo menos claro entre Alemania y Francia.

CUERPO DE EJÉRCITO DE REACCIÓN RÁPIDA (ARRC.): Donde participan todos los países de OTAN., y por ello los grupos de países antes analizados. Menos cohesión en este campo de los valores, con liderazgo británico y ninguna participación de Francia. Se puede suponer ciertos problemas de coordinación en su funcionamiento, aunque los resuelven publicando normas y procedimientos de funcionamiento.

Hay otras formaciones, como una fuerza anfibia combinada del Reino Unido y Holanda y Cuerpos de Ejército multinacionales, todas de países vecinos y razonablemente bien coordinadas.

Además de las Unidades también debemos considerar ciertos países como Suecia, Finlandia, Suiza, Irlanda y en fin, todos aquéllos que no forman parte de la UEO., pero sí de la UE. y que igualmente no forman parte de la OTAN. y, por otra parte, países como Turquía y Grecia que si bien forman parte de OTAN. tienen una vinculación bilateral conflictiva y su pertenencia a UE. es muy diferente.

Es aquí, en la situación de estos países, y en sus diferentes vinculaciones a las organizaciones que estamos tratando, donde se encuentran las dificultades de cohesión y el origen de los problemas políticos para llegar a decisiones conjuntas en una futura Política Europea de Seguridad Común, dentro de la UE., y en una acción común en el UEO. Si a lo anterior sumamos una posible ampliación la cosa se complicaría aún más. 


\section{Actitudes hacia la formación de unidades multinacionales}

Como complemento de lo anterior, es necesario hacer un repaso somero sobre las actitudes tradicionales de los diferentes países sobre el tema.

\section{Alemania}

Desde su creación en los años cincuenta, la Bundeswehr había sido preparada para trabajar completamente en el entorno multinacional de la OTAN. Aunque ciertas unidades se establecieron sobre bases nacionales, su entrenamiento, ejercicios y papel operativo fueron todos alineados en la estructura colectiva de la OTAN. Este punto de vista se reforzaba por la posición constitucional de que las fuerzas alemanas no podían empeñarse en otras acciones que las de defensa directa de la nación, de acuerdo con los términos del Tratado de Washington. Esto podría efectivamente apartar al Ejército alemán de las nuevas formaciones multinacionales en nuevo ambiente y que Alemania pudiera ofrecer sus recién estructuradas fuerzas para participar al máximo posible en formaciones multinacionales. Sin embargo, la reciente evolución efectuada en la interpretación de su Constitución, ha permitido que Alemania pueda desempeñar un cometido significativo en el evolucionado ambiente europeo de seguridad. En este sentido, acaba de crear un CE. multinacional junto con Dinamarca y Polonia, y ya participa activamente en operaciones fuera de sus fronteras, como es el caso de Kosovo.

\section{Francia}

El punto de vista de Francia era que el final de la guerra fría y la unificación alemana, y el fin de los derechos y responsabilidades compartidas en Alemania por Francia, Estados Unidos, Gran Bretaña y la Unión Soviética desde la Segunda Guerra Mundial, anularían cualquier requerimiento para el estacionamiento de tropas francesas en suelo alemán y llevaría a la desaparición de la estructura militar integrada de la OTAN., ante la que Francia había observado siempre una postura ambigua. El miedo a ser marginados en los movimientos para desarrollar una más grande identidad europea de defensa dentro de la Alianza Atlántica, que podría dar el liderazgo en este campo a Gran Bretaña o Alemania, pudo hacer reconsiderar este criterio al presidente Mitterrand y acordar con el canciller Kohl la creación de 
un Cuerpo Franco-Alemán, basado en la simbólica Brigada franco-alemana, alrededor de la cual podría construirse una identidad distinta de defensa europea. Este Cuerpo Franco-Alemán evolucionaría posteriormente hacia el EUROCUERPO, cuyo acuerdo para operar bajo paraguas OTAN. ha supuesto para Francia una aproximación indirecta a la estructura de fuerzas de esta organización. La actual postura francesa está claramente a favor de la formación de Unidades multinacionales.

\section{Estados Unidos}

Su postura está presidida por un dilema básico. Apuesta claramente por la OTAN., y por lo tanto, por la formación de las unidades multinacionales que su nueva estrategia preconiza. Desean estar fuertemente representados en su revisada estructura de Mandos y en la cadena de mando, para retener su influencia en los asuntos europeos y frenar la tendencia a desarrollar unas estructuras meramente europeas por parte de las naciones de la OTAN. que pudieran contrariar sus intereses estratégicos. Tener un pie en Europa es también una provechosa base avanzada de sus fuerzas para llevar a cabo propósitos nacionales fuera del área de la OTAN. Por otra parte, el proceso iniciado entre las naciones europeas para dotar de más multinacionalidad a sus estructuras de fuerza podría reducir la flexibilidad y libertad de acción americana, a lo que se añade que el Congreso de los EEUU. ha sido siempre reluctante a poner fuerzas americanas bajo mando no americano.

El dilema se realza con la intervención de la OTAN. en operaciones de apoyo a la paz bajo los auspicios de la ONU., especialmente en áreas próximas a la frontera de la OTAN., en las cuales la Administración USA. no quiere verse envuelta y persigue una política de mayor distanciamiento. Cuanto más intensa es una crisis, especialmente cuando implica acciones militares ofensivas, más se pide la participación y el liderazgo americanos. Su falta de inclinación a aceptar este papel debilita su posición en Europa. Por ello, los EEUU. ni pueden permanecer apartados del desarrollo de las fuerza multinacional, ni tampoco comprometerse hasta un punto que inhiba su flexibilidad nacional o que les implique en acciones militares que haría mejor en evitar.

\section{Reino Unido}

El punto de vista del Reino Unido ha sido más pragmático. En primer lugar, continúa manteniendo fuerzas británicas estacionadas 
en el continente, expresión de una importante demostración de su compromiso con la seguridad colectiva, y una muestra de su europeísmo. Paralelamente, resuelve el problema práctico que supondría llevar las tropas a su territorio, donde los cuarteles y los campos de instrucción son escasos.

En segundo lugar, una mayor contribución a las formaciones multinacionales mantendría la influencia británica en Europa, tanto en el campo militar como en el diplomático. En términos diplomáticos el Reino Unido podría controlar las nacientes estructuras paralelas europeas y estar en disposición de aprovechar las iniciativas europeas, especialmente la UEO., que considera menos comprometida que la OTAN. En términos militares, tal contribución puede justificar la asunción británica de un puesto importante de mando operativo, y puede influir en una ulterior evolución de la estructura militar.

En tercer lugar, el Reino Unido ve un mayor desarrollo de la estructura de fuerzas multinacionales como una forma de impedir una tendencia regresiva hacia el nacionalismo en materia de defensa y demás recortes presupuestarios. La postura británica también ayudará a mantener una fuerte presencia americana en Europa que Gran Bretaña cree no sólo fundamental para la fortaleza de la OTAN., sino también útil para asuntos internos europeos. El liderazgo USA. en la OTAN. actúa como un contrapeso a la poderosa conexión francoalemana en la que en materia de defensa Francia tiende a dominar.

\section{España}

España no podía permanecer indiferente a la proliferación en Europa de Unidades multinacionales. Como país de la Unión Europea, está integrándose en las estructuras comunes europeas en todos los campos, y la Defensa no es una excepción, saliendo del ya tradicional aislamiento. La política de defensa, dirigida por el Gobierno, está asumiendo una serie de compromisos internacionales que, por una parte, obligan a realizar esfuerzos de todo tipo para el cumplimiento pero, por otra, permiten disfrutar del marco de seguridad de los países occidentales. En este sentido, es de destacar el reciente paso dado por el Gobierno hacia las estructuras multinacionales de fuerzas al aprobar la plena participación de las FAS. españolas en la Estructura Militar Integrada de la OTAN.

Este espíritu de cooperación con otros países del entorno ha llevado a las Fuerzas Armadas españolas a cambiar su ámbito de actuación 
que iba, fundamental y casi exclusivamente, dirigido a la defensa de la soberanía del territorio español y que ha pasado, sin perder su carácter defensivo nacional, a ser capaz de cumplir sus misiones en cooperación con otras naciones fuera del territorio español.

Consecuente con esta política de defensa nacional, España ha intensificado su presencia en los foros de defensa y seguridad para ocupar el puesto que le corresponde por su peso económico, cultural, posición estratégica y prestigio mundial. Ahora bien, todavía queda mucho por hacer en este campo, pues como se desprende de lo expresado hasta ahora en el ambiente multinacional de defensa sigue siendo válido el lema de «tanto das, tanto recibes» y los retornos de prestigio e influencia en las grandes decisiones sobre seguridad sólo se producirán en función de nuestra aportación. Nuestra presencia en Kosovo podría ser un buen elemento de reflexión.

Por otro lado, esta integración de España obligará a la obtención y mantenimiento de un nivel de operatividad de sus ejércitos, similar al de los países con los que se integra en formaciones multinacionales, lo que obligará a la renovación de gran parte de su material.

\section{Otras Naciones}

Para las naciones OTAN. menos importantes como Bélgica, Holanda, Dinamarca, Portugal, etc. ..., una estructura de fuerza multinacional es esencial para la viabilidad de sus muy reducidas fuerzas terrestres. Ello podrá también permitir a estas naciones retener puestos de mando a nivel Cuerpo de Ejército, aunque sea rotando, lo que consideran necesario por razones de estructura de fuerzas, estatus e influencia, y para impedir que la estructura de mando sea dominada por naciones importantes lo que, por otro lado, es inevitable porque lo realmente importante para una Nación es participar activamente en las estructuras de mando multinacionales (Cuarteles Generales, Mando y Control, etc., ...) para poder liderarlas ya que las Unidades son más factibles de conseguir por, digamos, países de $2^{\circ}$ nivel sin que esto suponga un trato peyorativo.

Estas diferentes actitudes nacionales, objetivos y expectativas expuestas, pueden dar como resultado un conjunto de formaciones multinacionales sin una estructura uniforme, bien sean binacionales, trinacionales, tetranacionales; con distinto grado de integración, a nivel Cuerpo de Ejército, División o Brigada; con diferente dependencia del mando de la Gran Unidad Multinacional, control operativo, mando 
operativo, etc. Todas ellas son más el producto de consideraciones políticas que de requerimientos específicos militares.

Por ello, las fuerzas multinacionales son instrumentos de diferentes políticas exteriores, no sólo en un sentido militar, sino en el juego político entre naciones. Se usan para establecer status y credibilidad nacional, y tienen influencia en las percepciones de unos aliados sobre otros. Su efectividad dependerá de la cohesión de las unidades de las diferentes naciones, de la armonización de los diferentes caracteres, culturas y equipos, de la complementariedad de las diversas calidades y capacidades y de los acuerdos sobre el mando claramente definidos.

\section{Fuerzas multinacionales terrestres con participación de España}

\section{EUROCUERPO}

De acuerdo con la Declaración de La Rochelle (22 mayo 92) que establece las bases del EUROCUERPO, éste será empleado, de común acuerdo, en las siguientes misiones:

- Defensa Común de los aliados en aplicación del art. V del Tratado de Washington o del de Bruselas modificado.

- Mantenimiento y restablecimiento de la paz.

- Acciones humanitarias (asistencia en catástrofes, ayuda a refugiados y operaciones de evacuación).

La vocación europea de la Unidad la llevará a actuar prioritariamente en el marco de la UEO., de acuerdo con las orientaciones definidas en la UE. Asimismo, en aplicación del art. V del Tratado de Washington y con el fin de reforzar el pilar europeo de la Alianza, el EUROCUERPO podrá intervenir, como tal, para la defensa común de los Aliados, según las modalidades de un «Acuerdo Específico» a nivel político, ampliado con acuerdos técnicos a nivel operativo. Estos acuerdos definen las condiciones en las que el EUROCUERPO se pondría bajo la autoridad del mando apropiado de la OTAN. para su empleo, tanto en las Fuerzas de Defensa Principal como en la de Reacción Rápida.

Los diferentes ámbitos de actuación del EUROCUERPO podemos resumirlos de la siguiente forma:

- Ámbito del Art. V (Defensa Colectiva):

- Dentro de las Fuerzas de Defensa Principal de la OTAN., con prioridad de empleo en Centroeuropa. 


\section{La multinacionalidad en el campo de la defensa}

- En el marco de las Fuerzas de Reacción de la OTAN. según prevean los respectivos planes de contingencia.

- Ámbito de No-Art. V:

- En operaciones no amparadas en el Art. V y teniendo en cuenta los párrafos 42 y 43 de las directrices para la Defensa Aliada establecidas en el Concepto Estratégico de la Alianza de noviembre de 1.991, que permite el empleo de fuerzas militares de la misma para gestión de crisis que amenacen la seguridad de los países miembros y para operaciones de apoyo a la paz en el marco de la ONU.

- En Operaciones de Paz y Humanitarias como instrumento común de respuesta de la UEO. a petición de la ONU. y OSCE.

\section{EUROFOR. Y EUROMARFOR}

Con motivo de la Reunión Ministerial de la UEO. de Lisboa de 15 de mayo de 1995, los Ministros de Asuntos Exteriores y de Defensa de España, Francia e Italia lanzaron dos iniciativas político-militares mediante la constitución de EUROFOR. y EUROMARFOR. encaminadas a:

- Contribuir a proporcionar a Europa su propia capacidad militar, en particular en el área de proyección de fuerzas, y capacitar a los aliados europeos para asumir mayores responsabilidades de seguridad y defensa común.

- Proporcionar a los países de la UEO. una estructura multinacional básica para participar en operaciones UEO.

- Participar, de acuerdo con la Declaración de Petersberg, en iniciativas de Organizaciones Internacionales en el campo de mantenimiento de la paz y del desarrollo de la seguridad.

Los tres países manifestaron, en tal ocasión, su acuerdo para que Portugal participase en ambas iniciativas desde el inicio de su desarrollo, estando abiertas a los demás países miembros de la UEO.; serían desarrolladas simultáneamente y podrían actuar conjunta o independientemente.

Las misiones que pueden serles encomendadas son las definidas en la Declaración de Petersberg:

- Misiones humanitarias o de evacuación.

- Misiones de mantenimiento de la paz. 
- Misiones de fuerzas de combate para la gestión de crisis, incluidas las operaciones de imposición de la paz.

EUROFOR. y EUROMARFOR. están declaradas «Fuerzas a disposición de la UEO.» (FAWEU.) y serán empleadas prioritariamente en dicho marco. Las relaciones con la UEO. se han establecido de acuerdo con los documentos principales de esta Organización.

Ambas Fuerzas podrán igualmente emplearse, como tales, en el marco de la OTAN., para misiones no-Art. $V$ y con el fin de reforzar el pilar europeo de la Alianza. En cualquier caso, el cumplimiento de estas misiones no debe comprometer la participación de Unidades pertenecientes a las mismas en la misión de defensa común prevista tanto en el Art. $\mathrm{V}$ del Tratado de Washington como en el mismo artículo del de Bruselas modificado.

Además, podrá preverse el empleo de estas Fuerzas en aplicaciones de resoluciones del Consejo de Seguridad de NNUU., decisiones de la OSCE. o, eventualmente, de otras Organizaciones Internacionales.

En la actualidad establecida la base para su adecuada actuación al definirse sus relaciones y marco de actuación, se trabaja en el desarrollo de sus capacidades operativas en todos los aspectos necesarios, siendo aspecto principal la realización de ejercicios que permitan la activación de dichas fuerzas, adiestrarse y obtener enseñanzas de cara a mejorar su operatividad.

\section{Conclusiones sobre la multinacionalidad}

La Alianza Atlántica, en la cumbre de Londres en Julio de 1.990, ordenó una revisión completa de sus estructuras y estrategias, en el párrafo 14 de la Declaración de dicha cumbre se resaltaba el nuevo significado estratégico de la multinacionalidad. Éste afirmaba que la estructura de fuerza debía cambiar en lo fundamental, incluyendo entre sus características principales de cambio: «Se basará de forma creciente en los Cuerpos multinacionales, formados por unidades nacionales».

También la cumbre de la Unión Europea Occidental (UEO.) de Maaestricht, en 1.991, señaló como una de las medidas para fortalecer el papel operativo de esta organización la creación de unidades multinacionales que estarían a disposición de la UEO.

Se ve, por tanto, cómo las dos organizaciones de defensa más importantes de Occidente (OTAN. y UEO.) abogan por las unidades multinacionales para, además de servir de cohesión entre los países pertenecientes a cada una de ellas, hacer frente a los potenciales riesgos. 
Por otro lado, la simple capacidad militar es un factor cuantitativo que puede calcnlar su adversario potencial, pero el valorar las intenciones de un sliarza es el factor multiplicador de la cohesión, proporcionado por - der demostración multinacional de solidaridad en riesgos y cargas o partidas, lo que convierte la capacidad en disuasión. También se producen otros beneficios militares, como consecuencia del efecto sinergético de unir diversas capacidades multinacionales que generan un mayor entendimiento operativo o desde los beneficios prácticos de una creciente interoperatividad.

Es necesario considerar que cuanto más se avance en el unión política de las naciones como está ocurriendo en Europa, más comprometidos estarán sus ejércitos en unidades multinacionales $\mathrm{y}$, por ello, la coincidencia de la UE., UEO. y la OTAN. será crucial en el futuro y las misiones multinacionales claves en esa coincidencia.

En el caso concreto de Europa, si llegara a disponer de algunos Mandos Unificados, al estilo americano, ya se dispondría prácticamente del tan nombrado "Ejército europeo». Este paso puede estar a punto de darse si sale adelante y se conduce con habilidad la nueva estructura de OTAN., pues si los mandos regionales OTAN. fuesen de composición en su mayor parte europeos, con mando europeo y con unidades multinacionales europeas asignadas, ya tendríamos además de nivel táctico, el nivel operacional, con lo que habríamos dado un gran paso para disponer de un instrumento militar válido $\mathrm{y}$ profundamente europeo.

Por lo anterior no debemos olvidar el marco en el que se mueve la defensa europea que es el siguiente:

- OTAN. como organización de defensa básica (Art. V) y vínculo trasatlántico.

- Reforzamiento de la IESD. dentro de la futura estructura regional de OTAN.

- Reforzamiento de UEO. con capacidad de dirigir operaciones puramente europeas.

- Continuación de la unidad de acción de las FAS. europeas, cuyas doctrinas, sistemas de planeamiento y procedimientos son prácticamente comunes con un alto grado de identificación.

Ya en concreto, se pueden resumir las siguientes conclusiones sobre Unidades Multinacionales:

- Las reducciones de fuerzas sufridas en los ejércitos y el nacimiento de nuevos riesgos ha sido el condicionante para que países unidos por fuertes lazos económicos y diplomáticos y con una misma política exterior generen fuerzas multinacionales. 
- La participación en unidades multinacionales es una herramienta de la política exterior de los estados.

- Cada país tiene sus propias motivaciones para contribuir a una fuerza multinacional. Sin embargo, es causa común de participación el no quedar marginados del nuevo orden mundial, para tener peso en los organismos internacionales de defensa y discusión política.

- Tanto si la fuerza multinacional se establece por motivos políticos o para un objetivo militar específico, las autoridades deben de estar dispuestas a asumir sus costes, tanto políticos como financieros. Si no se cumple alguno de los compromisos contraídos con la fuerza multinacional, por motivos políticos, constitucionales o económicos, se resta credibilidad a toda la fuerza.

- Una vez que las naciones se han comprometido en una operación multinacional, han de subordinar los intereses nacionales al interés general.

- Las naciones tendrán que afrontar las inevitables consecuencias a las que, desde un punto de vista comercial e industrial, deben tender las estructuras de las fuerzas multinacionales.

- Desde el punto de vista militar, los principales requisitos con que debe contar una fuerza multinacional son la comunidad de doctrina y la estandarización de equipos.

- La organización, adiestramiento y empleo de una Unidad Multinacional es una operación compleja por la gran cantidad y variedad de temas que se deben coordinar.

- La logística continuará siendo una cuestión difícil de resolver en las fuerzas multinacionales. El modelo de nación marco, por el que una nación proporciona la mayor parte del apoyo logístico, podría ser la base de un sistema de apoyo en las unidades multinacionales que facilitaría enormemente éste, aunque todavía las cadenas logísticas nacionales determinan la capacidad de actuar de una fuerza multinacional.

\section{Epílogo}

Los acontecimientos recientes pueden darnos algunas claves en los conceptos de seguridad, a nivel global, y en el empleo de la multinacionalidad lo que suponen para los Ejércitos una serie de requisitos y capacidades, muchos de ellos suficientemente comentados en este trabajo. Ahora bien, hay algo más que es necesario considerar y que 


\section{La multinacionalidad en el campo de la defensa}

trasciende el campo puramente de técnica militar y que ya se ha expresado al hablar de la voluntad política de las naciones cuando deciden crear unidades multinacionales.

Es en este campo de las voluntades, las creencias y las sensibilidades donde reside la clave, pues las grandes motivaciones que hacían que un pueblo y sus Ejércitos se involucraran en un conflicto han evolucionado de forma desigual en el mundo y mientras para unos la intervención puede ser justificada por razones nuevas, como es evitar el sufrimiento de un pueblo, para otros continúa siendo sagrado el derecho a la no injerencia dentro de los límites de un Estado. Y estos sentimientos encontrados no sólo se dan entre las partes en conflicto sino dentro de cada una de ellas, de forma que la unanimidad es casi imposible, sin olvidar que cuando un conflicto estalla la identidad de criterios que sustentan una finalidad, sin valorar éticamente ésta, es muy importante para alcanzar resultados positivos.

Sin duda los medios de comunicación juegan un papel muy importante para aportar claridad o confusión, según se mire, a lo anterior. Hoy en día los conflictos son seguidos por los medios de comunicación casi en tiempo real y la propaganda en uno u otro sentido influyen en las opiniones públicas que a su vez lo hacen en los líderes que tienen capacidad de decisión y, por tanto, en el desarrollo de las operaciones. Desde luego, nunca fue fácil manejar un conflicto ni dirigir una guerra, pero es más sencillo cuando impera el maniqueísmo y se potencia esto en el sentido adecuado. Actualmente, sin embargo, es mucho más difícil establecer una clara diferenciación entre lo que se combate y lo que se defiende con lo que el respaldo público a las operaciones puede no ser todo lo firme que sería necesario en una operación bélica.

Por tanto, el manejo de la información, la explicación exhaustiva de la finalidad que se pretende y la justificación a todos los niveles es el único modo de mantener la cohesión y solidaridad de una coalición multinacional y que el pueblo entienda que hay circunstancias que exigen sacrificios haciendo que la idea de patriotismo trascienda hacia una "patria mundial», superando las ideas del nacionalismo antiguo y que sin renunciar a él comprenda que hay algo más que merece la pena y es la justicia y el respeto a los derechos individuales y colectivos de los seres humanos.

Ahora bien, si lo anterior es básico hay algo referente a las FAS. que es necesario tener en cuenta en su actuación como Unidades Multinacionales, y es que los frágiles equilibrios que se alcancen no pueden ser rotos por una actuación ineficaz de las fuerzas. Es decir, si de 
por sí será difícil lograr y mantener la solidaridad de las naciones que envían una Fuerza Multinacional a intervenir en cualquier parte del espectro del conflicto, sería imposible si surgieran rivalidades en el Mando y Control, acciones ineficaces por falta de integración técnica o problemas logísticos por poca interoperabilidad $y$, aún más, si se producen bajas por cualquiera de estos motivos. Es por ello que la responsabilidad de los militares en este nuevo escenario es crucial y el lograr la máxima eficacia en sus acciones no es un éxito sino un requisito imprescindible y un mínimo exigible.

Ahora bien, las naciones tienen que tener esto en cuenta a la hora de dotar a sus FAS. de recursos humanos y materiales y además de forma coordinada, puesto que seguir este camino previsible de estrategia de seguridad en el nuevo siglo sólo se puede conseguir con una alta y cara capacidad tecnológica y una muy clara y razonada finalidad de lograr un mundo mejor para todos en el que a cualquier posible acción para imponer estabilidad se traduzca en un mayor bienestar para los ciudadanos y, si es posible, sin imponerla sino que la clara determinación de hacerlo disuada a los potenciales lunáticos de la política de embarcarse en aventuras que todos deseamos queden superadas para siempre. 